\title{
Unilateral Atrophy of Fungiform Papillae Associated with Lingual Nerve Injury
}

\author{
Cecile L. Phan, Jodi L. Kashmere, Sanjay Kalra
}

Can. J. Neurol. Sci. 2006; 33: 428-429

The lingual nerve is at risk of injury during common dental procedures because of its proximity to the inferior alveolar nerve and the roots of the third molar tooth. Lingual nerve injury has been documented following extraction of wisdom teeth, ${ }^{1-3}$ dental anesthetic injections, ${ }^{4}$ and other endodontic procedures. ${ }^{5}$ We present a case of loss of somatosensory function and taste associated with the intriguing finding of fungiform papillae atrophy as a result of lingual nerve injury.

A 25 year old man with no previous medical history was evaluated in a general neurology clinic for numbness and loss of taste involving the right side of his tongue of two years duration. This began at the time of a difficult extraction of a right lower wisdom tooth with sudden, severe pain. Immediately thereafter, sensation and taste on the right half of the tongue were lost. This began to improve slowly about six months after the injury. However he still had altered sensation and taste when he was seen at our clinic two years later. Neurological examination revealed decreased sensation to pinprick over the anterior two thirds of the right side of the tongue and on the inner gingival mucosa of the right lower teeth. He was not able to identify salt or sugar applied to the anterior two thirds of the right side of the tongue. The number of fungiform papillae on the right side of the tongue was visibly reduced (Figure). The remaining examination of cranial nerves V and VII were normal. No other neurological deficits were found on exam.

The patient returned for follow up one year later (three years after injury) and reported some improvement in somatosensory function; unlike before, he could now appreciate whenever he bit the right side of the tongue. Hot and cold foods were detected more readily on that side. However, there was negligible change in taste function. Examination did not reveal any significant increase in the number of fungiform papillae on inspection. Sensation to pinprick was still reduced, but not as severe compared to the previous examination a year earlier. There was no recovery of taste function on the right side when tested again with salt and sugar.

The lingual nerve carries afferent somatosensory fibers from the anterior two thirds of the tongue, sublingual mucosa, and the lingual aspect of the lower gums. It also initially carries taste fibers from the anterior two thirds of the tongue which later enter the chorda tympani nerve. Therefore, lesions of the lingual nerve distal to its junction with the chorda tympani often result in altered sensation and loss of taste over the areas that they innervate. Our patient also had the interesting finding of atrophy

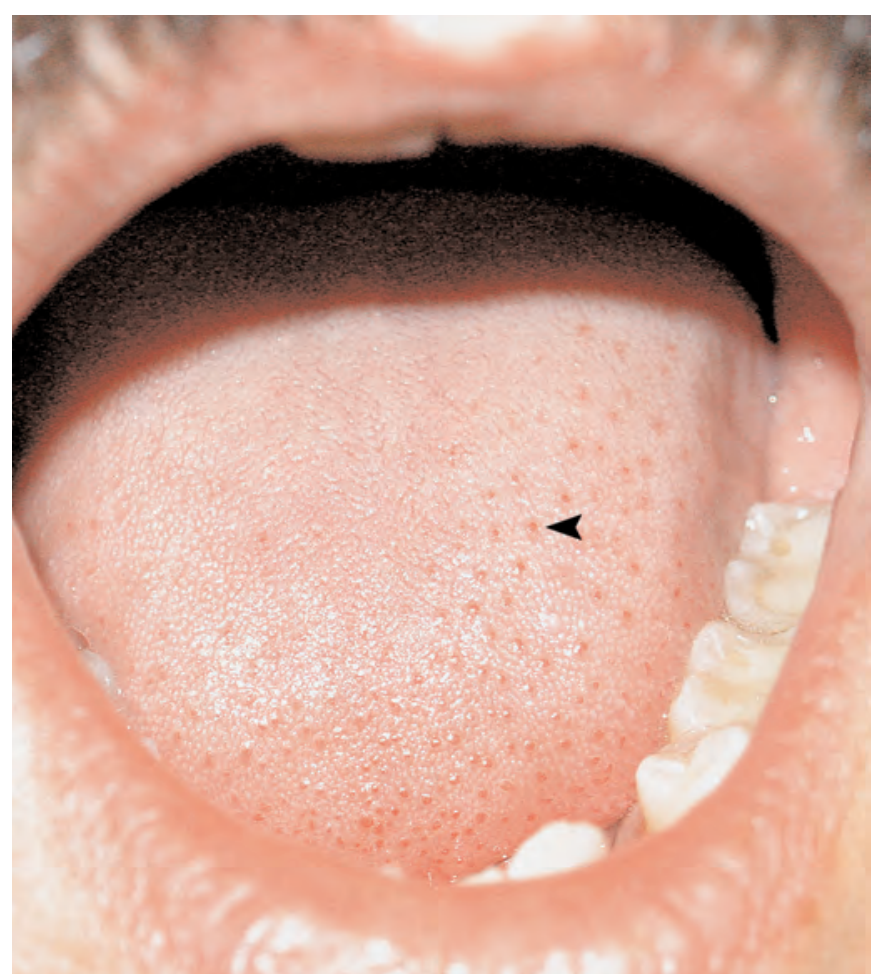

Figure. Fungiform papilli with normal, healthy appearance (arrow) on the left side of the tongue. The same papilli are not present on the right side of the tongue.

From the Division of Neurology, University of Alberta, Edmonton, Alberta, Canada

Received February 27, 2006. AcCePted in finAl Form September 2, 2006. Reprint requests to: Cecile Phan, 2F1-24 Walter Mckenzie Center, 8440-112 Street, Edmonton, Alberta T6G 2R7, Canada. 
of fungiform papillae. Fungiform papillae are localized predominantly to the anterior two thirds of the tongue, and they contain taste buds at their apices with a taste pore at the top. ${ }^{6}$ Fungiform papillae have dual innervation: the lingual nerve innervates the connective tissue and epithelium of surrounding taste buds and transmits somatosensory information; the chorda tympani innervation is confined to the taste buds and carries gustatory sensory information. ${ }^{7}$

Zuniga et $\mathrm{al}^{8,9}$ studied patients with partial to complete transection of the lingual nerve. They found that the density of fungiform papillae, as well as the ratio of pores per papillae were significantly reduced after lingual nerve transection. After their patients underwent lingual nerve repair by stump-to-stump coaptation, there was an increase in the number and density of fungiform papillae, taste pores, the number of pores per papillae, and some clinical recovery of taste.

In an elegant animal experiment, the chorda tympani nerve alone or chorda tympani - lingual nerve combined were transected followed by examination of the tongue at different time points. ${ }^{10}$ There were a portion of papillae with no taste buds in both groups, but the doubly denervated group had a significantly higher percentage of these papillae. This suggests that the lingual nerve formed collaterals to maintain neural support for some taste buds in the singly denervated group. Alternatively, the chorda tympany nerve might play a role in maintaining epithelial and connective tissue integrity. ${ }^{10}$ The maintenance of papillary structure is probably dependent on various trophic factors secreted by the lingual and chorda tympani nerves. A few candidate factors have been identified in animal models including calcitonin gene-related peptide (CGRP), neurokinin A (NKA), neural cell adhesion molecule (NCAM) and neuron specific enolase (NSE). ${ }^{11,12}$

The persistence of papillary atrophy appears to be an indicator of the extent of lingual nerve injury and can be prognostic of functional recovery. ${ }^{13-15}$ When sensory function of the tongue did not recover more than six months after lingual nerve injury, there was also a noticeable loss of fungiform papillae on that side. ${ }^{13}$ Similarly, transient atrophy with return to normal morphology can coincide with the return of normal sensation and initial paresthesias in the absence of atrophy usually heralds a complete recovery. ${ }^{14}$

This report serves to bring up an interesting clinical manifestation of a peripheral nerve injury that may be seen in general neurologic practice, namely loss of taste, somatosensory function, and visible atrophy of papillae on the tongue. Studies are warranted to better understand the pathophysiological mechanisms involved with an aim of developing viable therapeutic options. In particular, the therapeutic potential of human-specific gustatory trophic factors, perhaps in conjunction with surgical nerve repair, should be explored.

\section{REFERENCES}

1. Mason DA. Lingual nerve damage following lower third molar surgery. Int J Oral Maxillofac Surg. 1988;27:477-80.

2. Blackburn CW, Bramley PA. Lingual nerve damage associated with the removal of lower third molars. Br Dent J. 1989;167:103-7.

3. Carmichael FA, McGowan DA. Incidence of nerve damage following third molar removal: a West of Scotland Oral Surgery Research Group Study. Br J Oral Maxillofac Surg. 1992;30: 78-82.

4. Hotta M, Endo S, Tomita H. Taste disturbance in two patients after dental anesthesia by inferior alveolar nerve block. Acta Otolaryngol. 2002;546 Suppl:S94-8.

5. Graff-Radford SB, Evans RW. Lingual nerve injury. Headache 2003;43:975-83.

6. Victor M, Ropper AH. Disorders of the special senses. In: Victor M, Ropper AH, editors. Adams and Victor's principles of neurology, 7th ed. New York: McGraw-Hill; 2001. p. 243.

7. Whitehead MC, Frank ME, Hettinger TP, Hou LT, Nah HD. Persistence of taste buds in denervated fungiform papillae. Brain Res. 1987;192-5.

8. Zuniga JR, Chen N, Phillips CL. Chemosensory and somatosensory regeneration after lingual nerve repair in humans. J Oral Maxillofac Surg. 1997;55:2-13.

9. Zuniga JR, Chen N, Miller IJ Jr. Effects of chorda-lingual nerve injury and repair on human taste. Chem Senses. 1994;657-65.

10. Hard af Segerstad C, Hellekant G, Farbman AI. Changes in number and morphology of fungiform taste buds in rat after transection of the chorda tympani or chora-lingual nerve. Chem Senses. 1989;14:335-48.

11. Montavon P, Hellekant G, Farbman A. Immunohistochemical, electrophysiological, and electron microscopical study of rat fungiform taste buds after regeneration of chorda tympani through the non-gustatory lingual nerve. J Comp Neurol. 1996; 367:491-502.

12. Whitehead MC, Ganchrow JR, Ganchrow D, Yao B. Neural cell adhesion molecule, neuron-specific enolase and calcitoninrelated peptide immunoreactivity in hamster taste buds after chorda tympani/lingual nerve denervation. Neuroscience 1998; 83(3):843-56.

13. Ogden GR. Atrophy of fungiform papillae following lingual nerve damage - a poor prognosis? Br Dent J. 1989;167:332.

14. Cowan PW. Atrophy of fungiform papillae following lingual nerve damage - a suggested mechanism. Br Dent J. 1990;168:95.

15. Ogden GR. Loss of fungiform papillae. Br J Oral Maxillofac Surg. 1996;34:480. 